\title{
Cirrhosis Associated with the Australia Antigen in an Infant who Acquired Hepatitis from Her Mother
}

\author{
RALPH WRIGHT, ${ }^{*}$ M.D., D.PHIL., M.R.C.P. ; J. R. PERKINS,† ; B. D. BOWER, $\ddagger$ M.D., F.R.C.P., D.C.H. \\ D. W. JERROME, $\$ F.I.M.L.T.
}

British Medical fournal, 1970, 4, 719-721

\begin{abstract}
Summary: A 19-week-old English girl developed acute viral hepatitis, which became chronic with persistent hepatosplenomegaly and abnormal liver function tests. Liver biopsy at 1 year showed an active cirrhosis with multinucleated giant cells. The Australia (Au) antigen was detected repeatedly in the infant's serum by immunodiffusion and by electron microscopy at the time of the acute attack and during the development of cirrhosis. She had apparently acquired the hepatitis from her mother, who had had jaundice at the end of pregnancy and for one month thereafter, and who was subsequently shown to be a carrier of Au antigen. Particles with surface projections resembling paramyxoviruses were observed in two of the later specimens of the infant's serum.
\end{abstract}

\section{Introduction}

The Australia $(\mathrm{Au})$ antigen has been reported in association with some cases of chronic active liver disease, implying persistence of a hepatitis virus as the cause (Wright et al., 1969; Vischer, 1970). There are, however, striking geographical differences in the frequency with which this association occurs, and it is rare in Great Britain (Sherlock et al., 1970).

We here describe the development of cirrhosis in an English infant after apparently acquiring acute viral hepatitis from her mother. The Au antigen was detected repeatedly by immunodiffusion and by electron microscopy in the serum of both mother and child.

\section{Infant's History}

A 5-month-old girl was admitted to the Radcliffe Infirmary on 19 August 1969 with jaundice. She had been normal at birth apart from a laceration of the scalp sustained during delivery; birth weight $7 \mathrm{lb} .6 \mathrm{oz}$. $(3.3 \mathrm{~kg}$.). There had been no neonatal jaundice and development was normal. She had never been breast-fed. Her mother had been jaundiced at the end of the pregnancy and io: one month after delivery (see below). The baby's illness had begun with diarrhoea two weeks previously, at the age of 19 weeks. A mixture of neomycin, sulphaguanidine, and kaolin was given for a few days. Though the diarrhoea subsided and she appeared to be feeding well, obvious jaundice developed. The urine became dark and the stools pale.

On physical examination the infant was alert and well nourished. Moderate jaundice was present; the liver was palpable to two fingerbreadths below the right costal margin and the spleen was readily felt. Her weight was $15 \mathrm{lb} .15 \mathrm{oz}$. $(7.2 \mathrm{~kg}$.). Laboratory investigations on 20 August showed: bilirubin total 11.0 mg./100 ml., conjugated bilirubin $7.1 \mathrm{mg} . / 100 \mathrm{ml}$., alkaline phosphatase 26 King-Armstrong (K.A.) units; serum alanine aminotransferase (S.G.P.T.) greater than 110 units; one-stage prothrombin time (Owren's method) $27 \%$ of normal. Haemoglobin, W.B.C., and E.S.R. were normal. L.E. cells, Wassermann reaction, direct Coombs test, and toxoplasmosis dye test were negative. No viruses were grown from faeces and urine specimens. Au antigen was positive in the serum and negative in the urine. Five days later the bilirubin rose to $18.2 \mathrm{mg} . / 100 \mathrm{ml}$. and S.G.P.T. to 1,540 units. By 20 October the bilirubin had fallen to $1.8 \mathrm{mg}$. and S.G.P.T. to 860 units.

* May Reader in Medicine, Nuffield Department of Clinical Medicine. † Technician, Nuffield Department of Clinical Medicine. F Consultant Paediatrician.

S Research Officer, Department of Pathology, Radcliffe Infirmary, Oxford.
Mild scleral icterus was present intermittently, and the liver function tests were abnormal. The Au antigen was detected repeatedly in the serum (Fig. 1). The child ate well and weighed $20 \mathrm{lb} .(9.1 \mathrm{~kg}$.) at one year of age, but the liver and spleen increased in size and the E.S.R. rose to $40 \mathrm{~mm}$. in one hour (Westergren).

An open surgical biopsy of the liver was performed on 1 April 1970. The liver was enlarged and firm and its surface irregular. Histological examination showed gross disorganization of the normal architecture, with areas of irregular collapse and broad bands of fibrous tissue separating regenerating nodules. The fibrous septa contained a dense infiltrate of inflammatory cells, largely lymphocytes and plasma cells, with proliferation of bile ductules or pseudoducts and occasional islands of parenchymal cells. Active necrosis and cellular infiltration extended into some of the liver lobules isolating liver cells. Regeneration of parenchymal cells was a striking feature, and large multinucleated giant cells, singly or in clumps, were noted in some areas. No inclusion bodies were seen. The appearances were interpreted as indicating a chronic active hepatitis with cirrhosis and giant-cell transformation. Thin sections of liver tissue prepared for electron microscopy by conventional methods and stained with uranyl acetate and lead citrate did not show particles resembling Au antigen particles.

Levels of circulating immunoglobulins in the infant's serum were estimated by radial immunodiffusion. After a rise of the IgM level to $186 \mathrm{mg} . / 100 \mathrm{ml}$. at the time of the acute attack of viral hepatitis it fell to normal and remained so throughout, as did the IgA levels. IgG levels rose progressively during the development of cirrhosis to $2,280 \mathrm{mg}$. $/ 100 \mathrm{ml}$. Serial specimens of serum were examined for smooth muscle antibody, mitochondrial antibody, and antinuclear factors by indirect immunofluorescence. All were negative.

Treatment with prednisolone $20 \mathrm{mg}$./day was started on 5 April with improvement in liver function tests.

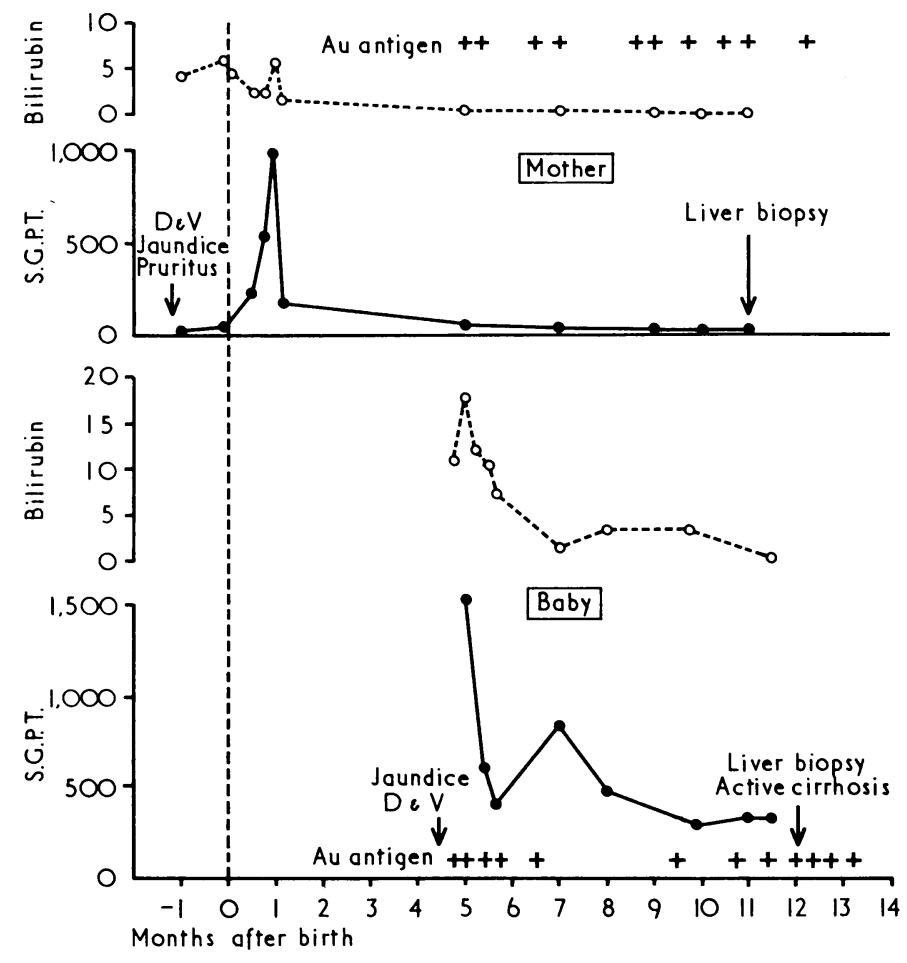

Fig. 1.-Liver function tests and $\mathrm{Au}$ antigen in the serum of mother and infant. 


\section{Mother's History}

This was the mother's first pregnancy and she was 20 years of age. She developed generalized pruritus at the thirty-sixth week, at the end of February 1969. This was followed a few days later by jaundice with dark urine and pale stools, diarrhoea, and vomiting. She denied having had blood transfusion or contact with a jaundiced person. She had, however, worked as a dentist's assistant until one month before the onset of symptoms. Physical examination was normal apart from jaundice and tenderness in the right upper quadrant of the abdomen. Labour was induced by rupture of membranes, and during delivery she sustained a perineal tear. On 21 March, the day of deliverv, laboratory investigations showed total bilirubin $5.4 \mathrm{mg} . / 100 \mathrm{ml}$., alkaline phosphatase 36.4 K.A. units, S.G.P.T. 47 units. After delivery the jaundice fluctuated, and on 16 April the S.G.P.T. was 992 units (Fig 1). Following the development of acute hepatitis in her infant the mother returned to hospital for investigation on 29 August. She was completely free from symptoms and liver function tests were normal, including the bromsulphthalein retention test. Au antigen was detected in her serum.

In retrospect it was thought likely that she had had acute viral hepatitis immediately before or immediately after delivery. Failure to develop recurrence of symptoms or biochemical abnormality on challenge with the contraceptive pill Norinyl-1 at this time, and the persistence of the abnormality of the S.G.P.T. for one month after delivery, ruled out intrahepatic cholestasis of pregnancy. A percutaneous liver biopsy was done on 23 February 1970. Histological examination showed a few small scattered foci of necrosis and cellular proliferation but $\mathrm{Au}$ antigen particles were not detected in the liver cell nuclei by electron microscopy.

\section{Special Laboratory Tests}

Serial specimens of undiluted serum from both mother and child were examined for the $\mathrm{Au}$ antigen by immunodiffusion as described previously (Wright et al., 1969) and by electron microscopy with negative staining (Almeida et al., 1969).

The antigen was present in the infant's serum at the time of che acute hepatitis and in all 11 specimens obtained over the following nine months during the development of cirrhosis. In addition, a weak line indicating the presence of antibody was present in the specimen taken on 13 May 1970. The Au antigen was detected in the specimen of serum taken from the mother on 29 August 1969 and in nine further specimens taken over the next nine months.

Typical Au antigen particles as previously described (Bayer et al., 1968; Almeida et al., 1969; Dane et al., 1970) were present in all specimens of serum from both mother and infant. A striking feature in the infant's serum was the presence of very long tubular forms of the antigen, several hundred $\mathrm{nm}$. in length, though small $(20 \mathrm{~nm}$.) rounded particles and large numbers of the larger particles (40 to $45 \mathrm{~nm}$. in diameter) were also observed (Fig. 2). Bridging of small and large particles and tubular forms, apparently by antibody was observed. The large rounded particles and large aggregates of antigen were more common in the later

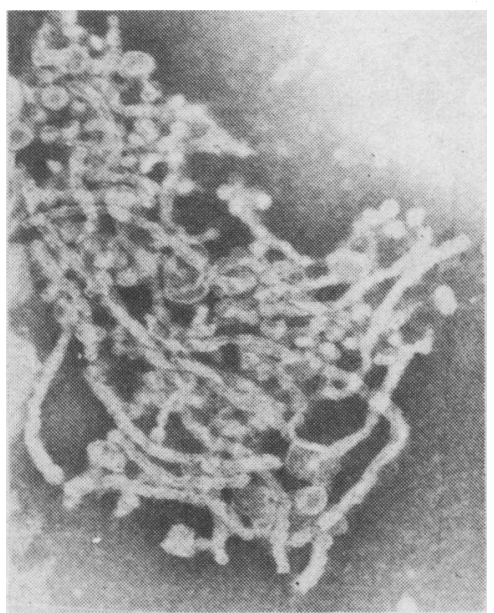

FIG. 2.-Au antigen particles detected in infant's serum $(\times 67,000)$.
Liver Function Tests in the Baby

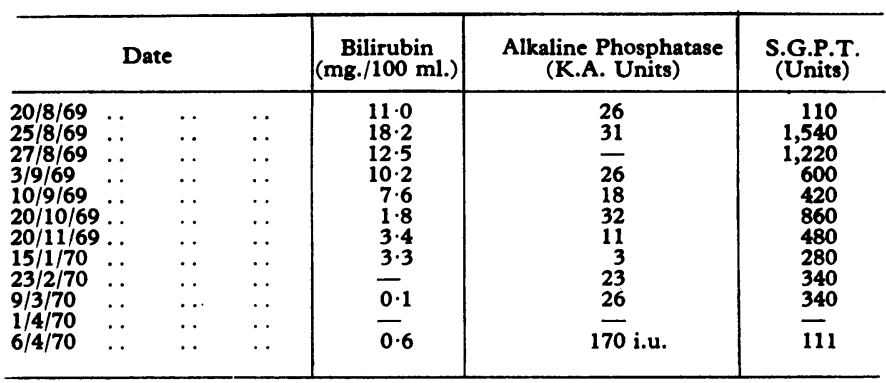

specimens. We also observed rounded and elongated particles about 50 by $250 \mathrm{~nm}$. with surface projections resembling corona or paramyxoviruses in two of the infant's recent serum specimens (Fig. 3). Tubular forms of the antigen, often aggregated in large clumps, were consistently observed in sera from the mother, but both large and small spherical particles were rare.

\section{Discussion}

The circumstances indicate that this infant developed an active cirrhosis as a result of progression of acute viral hepatitis acquired from its mother. Though acute viral hepatitis was not documented at biopsy the clinical features and the detection of the Au antigen during the acute attack in the infant and during convalescence in the mother strongly supports this diagnosis. An incubation period of four and a half months would be compatible with transplacental transmission at the time of delivery, but oral transmission of long-incubation hepatitis can occur (Krugman et al., 1967; Giles et al., 1969) and cannot be excluded in the present case.

Though the Au antigen may be detected in young infants (Krech and Sonnabend, 1970) we know of no reports of its detection in cord blood. The occurrence of a small laceration of the infant's scalp at the time of delivery would provide a portal of entry for infected material in blood, liquor, or faeces, and we believe this parenteral method of transmission to be the more likely. Indeed transmission of hepatitis from mother to infant appears to be uncommon, and if there is an effective barrier to the transplacental transmission of the virus, infection might occur only after such accidental inoculation.

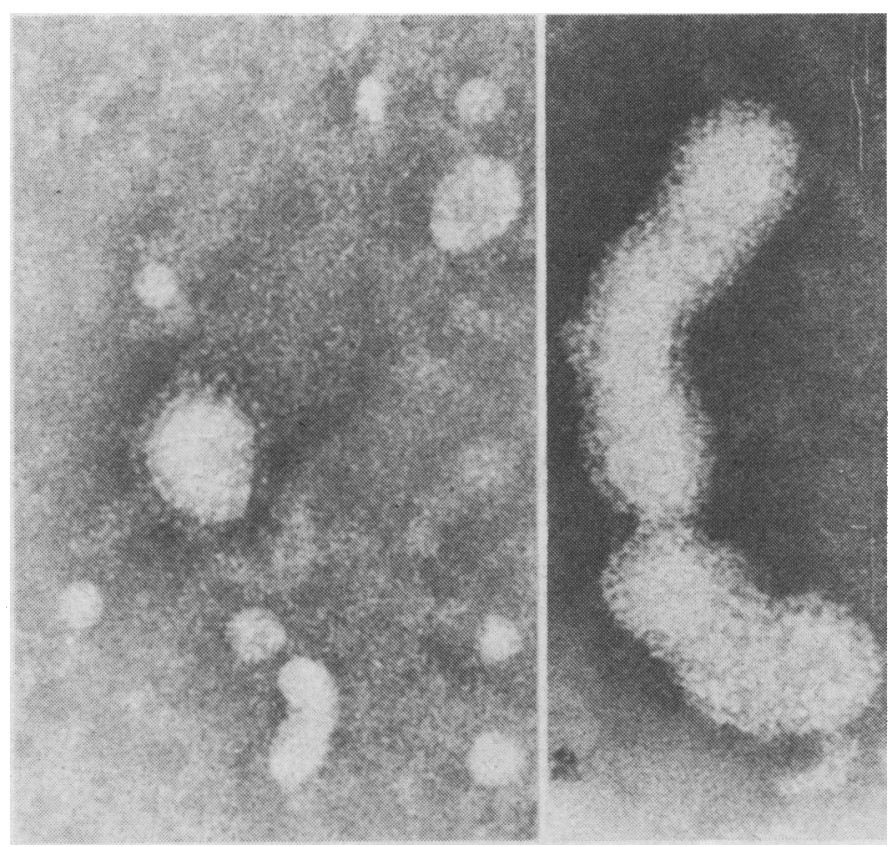

Fig. 3.-Particles with surface projections resembling paramyxoviruses detected in infant's serum $(x 200,000)$. 
Though the infant appeared well after the attack of acute viral hepatitis, there was persistent hepatosplenomegaly with raised transaminase and bilirubin levels, indicating active hepatitis during the progression to cirrhosis associated with giant cells. Aterman (1963) reported two siblings who died with giant cell hepatitis after an attack of infective hepatitis in the mother, and strongly favoured the view that giant cell hepatitis of the newborn is a form of viral hepatitis acquired from the mother. The detection of the $\mathrm{Au}$ antigen in the mother and infant here described provides evidence to support this view, and since the mother has become a chronic carrier her future children will presumably be at high risk of developing neonatal hepatitis.

It is not known whether the Au antigen is the virus itself, a viral protein coat, or a product of liver cell damage, but it is of interest that the large $(40-45 \mathrm{~nm}$.) particles thought by Dane et al. (1970) to be the parent virus were present throughout in the infant's serum. The significance of the large particles with surface projections resembling paramyxoviruses which we have detected in recent specimens of the infant's serum is also uncertain. We have observed similar particles in other specimens of serum from patients with acute and chronic hepatitis, including both Au-antigen-positive and Au-antigen-negative sera. They bear some resemblance to the coronavirus-like particles described by Zuckerman et al. (1970) in the serum of a patient with chronic active hepatitis.

The development of antibody to the $\mathrm{Au}$ antigen in the infant as detected by electron microscopy and by immunodiffusion and the rise in IgG levels is of interest in view of the suggestion of Almeida and Waterson (1969) that antibody may be responsible for tissue damage in hepatitis.

The mother's occupation as a dental assistant may have greatly increased her risk of becoming infected with the longincubation-period serum hepatitis virus, and the laceration of the infant's scalp may have facilitated its transmission, so that the circumstances under which the infant contracted $\mathrm{Au}$ antigen-positive chronic active hepatitis are exceptional.
Though such exceptional circumstances may be necessary in this country, the Au antigen may prove to be an important cause of cirrhosis in communities where the carrier state often occurs.

As with most other cases of Au-antigen-positive chronic active hepatitis the smooth muscle antibody was not present in this infant's serum though it is usually detected at high titre in the serum of patients with Au-antigen-negative chronic active hepatitis, thus raising the possibility that these two groups are aetiologically distinct (Sherlock et al., 1970; Vischer, 1970; Wright, 1970).

We thank Dr. F. O. MacCallum, Professor P. B. Beeson, and Dr. A. H. T. Robb-Smith for helpful criticism and advice; Mrs. Christine Ponsford, Miss Angela Terry, and Miss Tina Howkins for technical help; Professor P. R. Allison for facilities for electron microscopy; and Dr. J. G. G. Ledingham for permission to report on a patient under his care.

ADDENDUM: Since this report was submitted for publication C. Sirtori, British Medical fournal, 1970, 3, 768, has detected structures resembling paramyxoviruses by electron microscopy of liver biopsies from children with acute viral hepatitis which appear to be identical to one of those illustrated in Fig. 3 which we have observed in this infant's serum.

\section{REFERENCES}

Almeida, J. D., and Waterson, A. P. (1969). Lancet, 2, 983.

Almeida, J. D., Zuckerman, A. J., Taylor, P. E., and Waterson, A. P. (1969) Microbios, 1, 117.

Aterman, K. (1963). American fournal of Diseases of Children, 105, 395.

Bayer, M. E., Blumberg, B. S., and Werner, B. (1968). Nature, 218, 1057 Dane, D. S., Cameron, C. H., and Briggs, M. (1970). Lancet, 1, 695 .

Giles, J. P., McCollum, R. W., Berndtson, L. W., and Krugman, S. (1969). New England Fournal of Medicine, 281, 119.

Krech, U., and Sonnabend, W. (1970). Lancet, 1, 779.

Krugman, S., Giles, J. P., and Hammond, J. (1967). Fournal of the American Medical Association, 200, 365.

Sherlock, S., Fox, R. A., Niazi, S. P., and Scheuer, P. J. (1970). Lancet, 1, 1243.

Vischer, T. L. (1970). British Medical fournal, 2, 695.

Wright, R. (1970). Lancet, 1, 521.

Wright, R., McCollum, R. W., and Klatskin, G. (1969). Lancet, 2, 117

Zuckerman, A. J., Taylor, P. E., and Almeida, J. D. (1970). British Medical fournal, $1,262$.

\section{Preliminary Communications}

\section{Bioassay of Thyroid Stimulating Hormone Using the Goldfish}

British Medical fournal, 1970, 4, 721-723

\begin{abstract}
Summary : A new method for the bioassay of thyroid stimulating hormone using goldfish is described. The technique can detect thyroid stimulating substances in euthyroid unconcentrated plasma. Early results show that the method compares well with other techniques. Some evidence has been obtained which suggests that in primary myxoedema there may be some impairment of the thyropituitary "servo-mechanism" in older patients.
\end{abstract}

\section{INTRODUCTION}

Many methods for the bioassay of thyroid stimulating hormone (T.S.H.) have been developed (Brown, 1957), but there has been considerable difficulty in finding a simple technique with the necessary sensitivity to detect thyroid stimulating activity in normal plasma. Others have shown that fish can be used as subjects for the bioassay of T.S.H. (Fontaine and Fontaine, 1956; Brown, 1957); and it has also been shown that fish are very sensitive to other thyroid stimulating substances such as heterothyrotrophic factor. The available evidence (Fontaine and Burzawa-Gérard, 1966; Fontaine, 1969) suggests that heterothyrotrophic factor is indistinguishable in its activity from mammalian follicle stimulating hormone (F.S.H.). Nevertheless, the term heterothyrotrophic factor has been retained because it remains to be shown that this holds true in the bioassay system described here.

Though immunoassay has become popular as a means of assaying T.S.H. the method has some limitations. The antigen used to raise the specific antibody (human T.S.H.) is still an impure substance (Bates and Condliffe, 1966) and its very specificity excludes the study of other physiologically active substances in human plasma such as long-acting thyroid stimulater (L.A.T.S.) (Adams and Purves, 1956) and possibly heterothyrotrophic factor (Fontaine and Lopez, 1965). It also excludes the discovery of any further such substances that may be present. While T.S.H. extracts remain impure it will be necessary to have effective bioassay procedures for reference.

A brief description of the method adopted, together with some preliminary results, is given here. Initially we thought that hypophysectomy would be needed to achieve sufficient sensitivity in the goldfish, and this was tried, but further experiments showed that heated intact fish gave results which were even more sensitive and precise.

\section{METHOD}

Goldfish of the comet variety, 2-3 in. $(5-7.5 \mathrm{~cm}$.) long, are kept in compartments in a 100-litre tank. All compartments are interconnected in a common environment with central filtration and heating and a pumped circulation of water. The water temperature is gradually increased over two days until 